\title{
Economic and Sustainability Comparative Study of Wood Pellets Production in Portugal, Germany and Sweden
}

\author{
L.J.R. Nunes ${ }^{1,2}$, J.C.O. Matias ${ }^{1}$ and J.P.S. Catalão ${ }^{1,3,4}$ \\ ${ }^{1}$ University of Beira Interior \\ R. Fonte do Lameiro, 6200-001 Covilhã (Portugal) \\ Phone: +351 275329 914, Fax: +351 275329972 \\ e-mail: d1213@ubi.pt; matias@ubi.pt; catalao@ubi.pt \\ ${ }^{2}$ YGE - Yser Green Energy SA, Zona Industrial de Taboeira, 3800-055 Aveiro, Portugal \\ ${ }^{3}$ INESC-ID, R. Alves Redol, 9, 1000-029 Lisbon, Portugal \\ ${ }^{4}$ IST, University of Lisbon, Av. Rovisco Pais, 1, 1049-001 Lisbon, Portugal
}

\begin{abstract}
During the last decade wood pellets consumption grew rapidly. In this paper the development of the wood pellet production factors for markets in Germany, Sweden and Portugal are compared. Domestic market prices for pellet production factors as well as domestic market prices for pellets variation are analysed. The analysis are based on two model plants, representing the first common technologies for small scale production based on dry sawdust sources, and the second represents large scale production based on wet materials. The results show how differences in costs of raw materials, energy and labour affects wood pellets production. The economic sustainability for European pellet producers depends on their domestic markets as internationally traded pellets are priced lower than their production costs, being Portugal an exception due to lower labour and raw materials costs. Future pellet production will be based on wet raw materials such as logs and wet sawdust. These raw materials are also demanded by pulp and paper or fiberboard industries. The transition from smaller wood pellets plants using dry raw materials to larger plants using wet raw materials, can be expected to follow comparative advantages regarding raw materials, energy costs and economies of scale.
\end{abstract}

\section{Key words}

Wood pellets, production costs, biomass.

\section{Introduction}

The consumption of wood pellets has grown rapidly over the last ten years, leading in Portugal, and a little for all over Europe, to the installation of several large capacity production plants, which exports $90 \%$ of its capacity to northern Europe markets, mainly for the production of electricity and residential district heating [1].
This paper compares the development of the variables involved in the production of wood pellets in Portugal with other European markets, such as Germany and Sweden, and how the domestic prices of wood pellets and domestic costs of production factors may vary among different countries.

The analysis is based on two production model plants. The first is a small-scale unit, based on the production of wood pellets with dry raw materials, mainly sawdust, while the other represents a model of large-scale production based on the use of wet raw materials. The results show how differences in the costs of raw materials, energy and labour, affects the final price of wood pellets and therefore also the development of wood pellets industry Portugal, Germany and Sweden, being the first one a newcomer with a fast growing industry, profiting of the existence of large untouched resources, and the two last the most experienced and stabilized markets where wood pellets had all initial development and still exports know-how [2].

Unlike their USA and Canada counterparts, European producers have higher costs of raw materials, and in many cases also higher energy costs, indexing the profitability of the production of wood pellets in Europe on the volume of its domestic markets for both electricity generation and heating, since wood pellets from outside Europe have prices lower than their production costs [3]. The future production of wood pellets will mandatorily evolve to the use of wet raw materials and increment of production capacity, benefiting from the competitive advantages related to economies of scale [4]. The development of wood pellets production and consumption differs greatly between countries, and it is of high interest for forestry, forest industries and wood pellets producers to get better knowledge about the causes for the differences and their development [5]. 
The main objectives of this paper are to compare the development of market, economic and sustainability conditions in Portugal, Germany and Sweden, and to analyse how domestic market prices for pellets, capital costs, feedstock, energy and labour vary between these countries. Also how these factors affect the economic sustainability of wood pellets production in each country will be analysed.

European countries represent different developments regarding pellet production compared to the USA and Canada where wood pellets production is largely increasing, mainly with the aim of exportation to Northern European countries, where consumption is growing each year, being also the first destination for the Portuguese wood pellets production [6].

Dry sawdust have historically been the main raw material for wood pellets production due to low prices, a relatively homogenous composition and, the most important of all, no need for thermal drying of the feedstock [7].

Declining activity in the wood industry, closely interconnected with construction industry in Portugal and facing a deep crisis, has reduced the availability of raw materials for many wood pellets plants [8].

Economic sustainability for European pellet producers, in particular to countries like German and Sweden, depends on their domestic markets as the international pellet prices are lower than European productions cost [9]. By the other hand, Portugal depends on external markets, because exports the majority of national production [10].

Wood pellets production is, to a larger extent, based on wet raw materials such as wood chips, round wood and wet sawdust. These raw materials are also demanded by other wood-based industries like the traditional forest industries, but also for bioenergy production as wood chips and firewood. Increased feedstock prices must hence be expected if the pellet production shall continue to increase [11].

The transition from smaller pellet plants using dry feedstock to larger plants using wet feedstock in future pellet production can be expected to follow comparative advantages, especially regarding feedstock and energy costs, but also with respect to economies of scale [12].

Long term development of biomass costs and wood pellet production costs depends on the development for biofuels, bio-refineries and other technologies for renewable power production as well as the development in the forest industries.

\section{Material and methods}

\subsection{Production Technologies}

The present analysis is based on a model plant that represents a small scale pellet production $(10,000 \mathrm{t} / \mathrm{y})$ based on dry sawdust, and a plant representing large scale production $(100,000 \mathrm{t} / \mathrm{y})$ based on wet materials.

Information required about pellet production was searched from available literature and consultations with actors in the Portuguese and European market. The chosen models reflect the economies of scale for the majority of pellet producers in the analysed markets.

It was assumed availability of dry feedstock but not necessarily full-time operation for the small production plant. By other hand the large production plant reflects full-time operation with wet materials.

Fig. 1 shows a typical pellet production line. The exact energy demand for drying depends on relative temperature, air humidity and particle size. After drying are pelletized and forwarded to a counter stream cooler and from there finally to a storage facility or bagging.

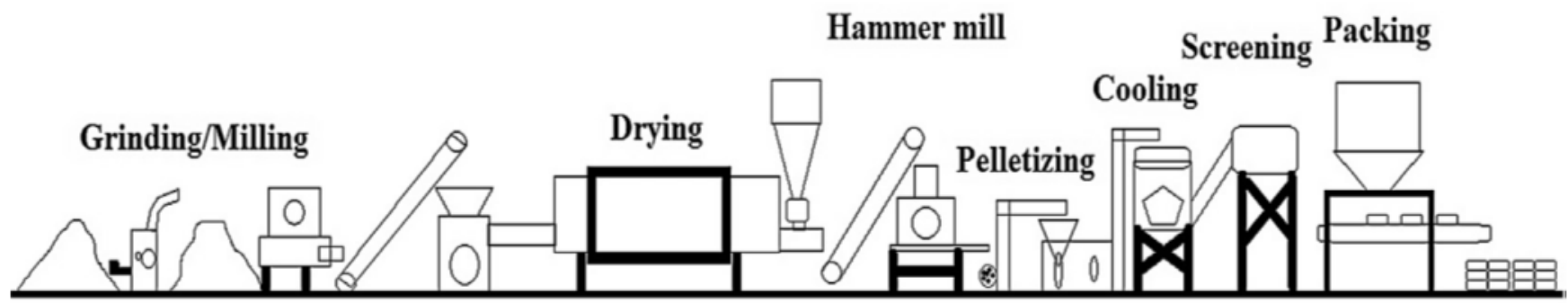

Fig. 1. Schematic layout of a typical biomass pellets plant [13].

Table 1 shows the specifications of the model plants: 4 workers per shift in the small and 8 workers per shift in the large scale plant were assumed.

The operation hours are set to $4000 \mathrm{~h} / \mathrm{y}$ for the small and $8000 \mathrm{~h} / \mathrm{y}$ for the large scale plant.
Table 1. Specifications for model wood pellet plants.

\begin{tabular}{|c|c|c|c|}
\hline Factor & Small plant & Large Plant & Unit \\
\hline Production capacity & 10,000 & 100,000 & $\mathrm{t} / \mathrm{y}$ \\
\hline Wood consumption & $100 \%$ dried & $100 \%$ wet & \\
\hline Heat consumption & 0 & 3.6 & $\begin{array}{c}\mathrm{GJ} / \mathrm{t} \\
\mathrm{pellets}\end{array}$ \\
\hline Power consumption & 40 & 100 & $\begin{array}{c}\mathrm{kWh} / \mathrm{t} \\
\mathrm{pellets}\end{array}$ \\
\hline Total staff & 8 & 40 & Workers $/ \mathrm{y}$ \\
\hline
\end{tabular}




\section{Market conditions}

\subsection{Development of domestic pellet markets}

\subsubsection{Germany}

German market is characterized by a large continuous increase of production and consumption. The majority of pellet consumers are private households. In Germany, pellet based electricity generation by co-firing is not common, and pellets are a minor feedstock for biomass in CHP plants, that operates mainly with coal and refuse derived fuels [14]. Average price at mill gate for certified pellets was $175 € / t$ in 2012 [15]. In 2012 the bid price for imported pellets from USA and Canada was $135 € / \mathrm{t}$ CIF Rotterdam, and the corresponding price for pellets from Central and Eastern Europe was $145 € / \mathrm{t}$ at mill gate [16].

\subsubsection{Sweden}

Sweden is one of the largest consumers of wood pellets in the world with a consumption of about 2,500,000 $\mathrm{t}$ in 2012 [17]. About $40 \%$ are consumed by large district heating plants, which have converted from coal. Swedish Energy Agency [18] reported a price for wood pellets delivered at district heating plants in 2012 of $145 € / t$.

\subsubsection{Portugal}

The wood pellets industry in Portugal consists of 8 plants of large capacity $(>100,000 \mathrm{t} / \mathrm{y})$ and more 16 small or medium plants $(<40,000 \mathrm{t} / \mathrm{y})$ with a total annual production of 1,200,000 t/y. All the large plants are based on pulpwood or wood chips as the main raw materials, while the small and medium plants uses majorly dry materials. Domestic pellet production increased steadily from 120,000 $\mathrm{t}$ in 2006 and reached 1,200,000 $\mathrm{t}$ in 2012 [19]. The consumption of wood pellets has grown much slower and is estimated to be $120,000 \mathrm{t}$ in 2012 . For these figures, wood pellets represent a very small fraction of the energy market in Portugal yet. In 2012 the average price at mill gate for certified pellets was $160 € / \mathrm{t}$. When sold in bulk the price was $135 € / \mathrm{t}$. About $10 \%$ of the market is for pellet stoves in private households and for industrial boilers, mainly operating in textile industry, while $90 \%$ is exported in bulk for Northern European countries like Belgium, Sweden or Denmark [20].

\subsubsection{Market structures}

Table 2 gives an overview of the market characteristics for pellets in the three countries covered by this study [21].

Table 2. Characteristics of the analyzed pellet markets.

\begin{tabular}{|c|c|c|c|c|c|}
\hline$\underset{\Xi}{\Xi}$ & 总异导 & 总高芯 & 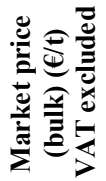 & 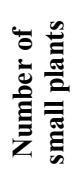 & 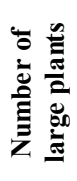 \\
\hline Germany & $1,600,000$ & $1,100,000$ & 198 & 30 & 11 \\
\hline Sweden & $1,600,000$ & $2,000,000$ & 175 & 30 & 6 \\
\hline Portugal & $1,200,000$ & 120,000 & 165 & 16 & 8 \\
\hline
\end{tabular}

\subsection{Biomass factor costs}

\subsubsection{Biomass costs for pellet production}

The costs for feedstock used for the cost calculations are reported in Table 3 and are based on average market prices in the different countries obtained with local suppliers.

Table 3. Estimated feedstock costs at pellet mill gate.

\begin{tabular}{|c|c|}
\hline Country & $\boldsymbol{\epsilon} /$ t (dry tonne) \\
\hline Germany & 90 \\
\hline Sweden & 92 \\
\hline Portugal & 84 \\
\hline
\end{tabular}

\subsubsection{Other factor costs}

Electricity costs can vary by scale and it is assumed that are $20 \%$ higher in the small production units. Heat prices vary locally and were obtained with an European dryer manufacturer with experience in all the countries studied here.

Table 4 shows the electricity prices for industry including grid rent and energy use tax. Labour costs including nonwage costs are shown in Table 5.

Table 4. Energy costs.

\begin{tabular}{|c|c|c|}
\hline Country & $\begin{array}{c}\text { Electricity } \\
\boldsymbol{\epsilon} / \mathbf{M W h}\end{array}$ & $\begin{array}{c}\text { Heat } \\
\boldsymbol{€} / \mathbf{G J}\end{array}$ \\
\hline Germany & 100 & 6 \\
\hline Sweden & 60 & 6 \\
\hline Portugal & 90 & 4 \\
\hline
\end{tabular}

Table 5. Labour costs.

\begin{tabular}{|c|c|}
\hline Country & $\begin{array}{c}\text { Labour costs } \\
\boldsymbol{\epsilon} / \mathbf{h}\end{array}$ \\
\hline Germany & 36 \\
\hline Sweden & 34 \\
\hline Portugal & 20 \\
\hline
\end{tabular}

Other costs such as capital costs, interest rates, transport costs for pellets and other production costs than labour, biomass and energy are assumed to be the same in the analyzed countries and are shown in Table 6.

Table 6. Other costs.

\begin{tabular}{|c|c|c|}
\hline Cost factor & $\mathbf{1 0 , 0 0 0} \mathbf{t} / \mathbf{y}$ & $\mathbf{1 0 0 , 0 0 0} \mathbf{t} / \mathbf{y}$ \\
\hline Interest rate & \multicolumn{3}{|c|}{$6 \%$} \\
\hline Investment $(\boldsymbol{\epsilon})$ & $1,000,000$ & $10,000,000$ \\
\hline Maintenance $(\boldsymbol{\epsilon} / \mathbf{t})$ & 5 & 12 \\
\hline Transport $(\boldsymbol{\epsilon} / \mathbf{t})$ & \multicolumn{2}{|c|}{12} \\
\hline
\end{tabular}

\subsubsection{Total production costs}

Estimated production costs $(€ / \mathrm{t})$ for pellets are shown in Figure 2.

The production costs for the smaller plants are very similar to the production costs of the larger plants in all countries. 


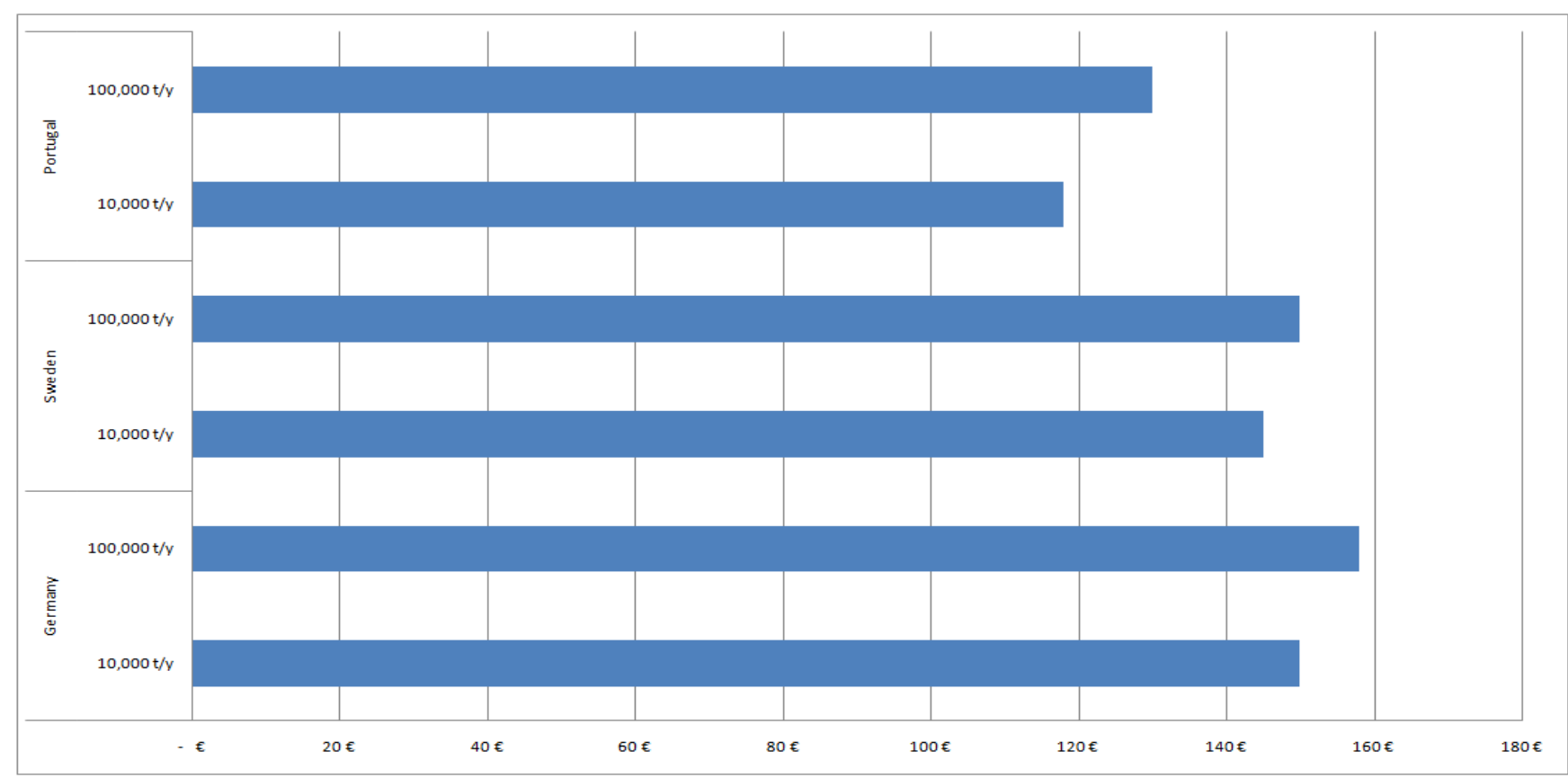

Fig. 2. Pellet production cost per country.

Portugal has lower production costs than the other countries due mainly to lower labour costs and lower heating energy costs. Analysing the cost structure showed in the last tables, about $60 \%$ of the total costs are expenses for raw materials and raw materials transport. Labour, energy and capital costs are comparable in the three countries. Hence, the way to cut production costs and raise profitability is to minimize feedstock and transportation costs.

\section{Discussion}

\subsection{Methodology}

The cost part of the study is based on two types of wood pellets plants, and estimation of their production inputs. The major uncertainty in this study is that each country has production units that differ from the two types here assumed. It is also a prevailing problem that pellet plants based on dry sawdust compete with the availability of dry raw materials within their procurement area. Low rate of working hours implies higher costs for labour and maintenance. Other factors of uncertainty are the price of pellets, which may vary considerably with quality and market segment.

\subsection{Markets}

Dry raw materials are by-products of the several industries like furniture production or lumber. In Portugal industries like these are traditional, but due to the still pending economic crisis, their production volumes came down and the waste amount reduced significantly. In addition, these materials have low bulk density, with average values of $150 \mathrm{~kg} / \mathrm{m}^{3}$, which means that transportation and storage are limited by volume and is comparatively costly. Competition for wet feedstock such as logs, wood chips, pulpwood or forest residues vary depending on the country.

Wood pellets production based on wet raw materials relies on high volumes and continuous operation (usually $>40,000 \mathrm{t} /$ year), while the small scale wood pellets industry needs dry raw materials. The potential increase in the availability of dry feedstock is limited by low increase in sawn wood production and alternative local use of the raw materials. This implies lower price elasticity for dry raw materials compared to wet raw materials when used for wood pellets production.

There are differences in the markets for the countries analyzed. Pellet consumption in Sweden is many times times higher than in Portugal, even if these countries have both large forest resources. A more active policy of substituting coal and oil based fuels with wood pellets in central heating facilities is the explanation for the large pellet consumption in Sweden compared to other countries. The same is occurring with the still very slow growing of pellets consumption in Portugal, with the naphta and natural gas as fuel replacement in industrial boilers. None of the three countries uses pellets for cofiring in CHP plants like in the Netherlands or UK. This may be an interesting possibility for future increase in the use of pellets, mainly if the technology evolutes to torrefaction combined systems.

\subsection{Costs}

Biomass costs are rather similar in the three countries studied, being just slightly slower in Portugal. European variation of both biomass and pellet costs can however reduce the profitability in many regions. Reduced availability of dry residues from sawmills implies higher biomass costs and/or low capacity utilization for many pellet plants. 
Germany has by far the highest electricity costs for the large scale mill, with the Sweden having the lowest electricity costs.

\section{Conclusions}

Historically dry sawdust and chips have been the main raw materials for wood pellets plants due mainly to nonexcessive prices, already dried and its homogenous composition. Declining activity in the traditional forest industry has reduced the availability of dry raw materials for many wood pellets plants.

In Europe, the economic sustainability for wood pellets producers depends mainly on their domestic markets as the international pellet prices are lower than European productions cost, with exception for the Portuguese case still devoted to exportation instead of internal consumption. In these countries, no direct support for wood pellets occurs, implying that wood pellets must be competitive due to price, quality and logistical operations.

In a near future wood pellets production will be based on wet raw materials, competing directly with other industries like pulp and paper or fibreboard industries. In this scenario must be expected an increase in raw materials prices once wood pellets production will grow continuously.

Transition from small wood pellets plants using dry raw materials to larger plants using wet feedstock in future pellet production can be expected to follow comparative advantages, especially regarding feedstock and energy costs, but also with respect to economies of scale.

Increased production in the medium term will probably take place in larger mills based on pulpwood which offers more secure biomass supply compared to dry residues. Increased biomass costs and hence pellet prices must be expected over time, but do not necessarily imply that wood pellets will lose competitiveness compared to other technologies or prevailing energy prices.

Long term development of biomass costs and wood pellet production costs depends on the development for biofuels, bio-refineries and other technologies for renewable power production as well as the development in the forest industries.

\section{Acknowledgement}

This work was supported by FEDER funds (European Union) through COMPETE and by Portuguese funds through FCT, under Projects FCOMP-01-0124-FEDER020282 (Ref. PTDC/EEA-EEL/118519/2010) and PEstOE/EEI/LA0021/2013. Also, the research leading to these results has received funding from the EU Seventh Framework Programme FP7/2007-2013 under grant agreement no. 309048 .

\section{References}

[1] Monteiro, Eliseu, Vishveshwar Mantha, and Abel Rouboa. "Portuguese pellets market: Analysis of the production and utilization constrains." Energy Policy 42 (2012): 129-135.

[2] Monteiro, Eliseu, Vishveshwar Mantha, and Abel Rouboa. "The Feasibility of Biomass Pellets Production in Portugal." Energy Sources, Part B: Economics, Planning, and Policy 8.1 (2013): 28-34.

[3] Ferreira, Pedro T., Manuel E. Ferreira, and José C. Teixeira. "Analysis of Industrial Waste in Wood Pellets and Co-combustion Products." Waste and Biomass Valorization (2013): 1-14.

[4] Uasuf, Augusto, and Gero Becker. "Wood pellets production costs and energy consumption under different framework conditions in Northeast Argentina." Biomass and Bioenergy 35.3 (2011): 1357-1366.

[5] Alakangas, E., et al. "EUBIONET III-Solutions to biomass trade and market barriers." Renewable and Sustainable Energy Reviews 16.6(2012):4277-4290.

[6] Zhang, Yimin, et al. "Life cycle emissions and cost of producing electricity from coal, natural gas, and wood pellets in Ontario, Canada." Environmental science \& technology 44.1 (2009): 538-544.

[7] Karkania, V., E. Fanara, and A. Zabaniotou. "Review of sustainable biomass pellets productionA study for agricultural residues pellets' market in Greece." Renewable and Sustainable Energy Reviews 16.3 (2012): 1426-1436.

[8] McKechnie, Jon, et al. "Forest bioenergy or forest carbon? Assessing trade-offs in greenhouse gas mitigation with wood-based fuels." Environmental science \& technology 45.2 (2010): 789-795.

[9] Magelli, Francesca, et al. "An environmental impact assessment of exported wood pellets from Canada to Europe." Biomass and Bioenergy 33.3 (2009): 434-441.

[10] Olsson, Olle, Bengt Hillring, and Johan Vinterbäck. "European wood pellet market integration-a study of the residential sector." biomass and bioenergy 35.1 (2011): 153-160.

[11] Eriksson, Lisa, and Leif Gustavsson. "Comparative analysis of wood chips and bundles-Costs, carbon dioxide emissions, dry-matter losses and allergic reactions." Biomass and Bioenergy 34.1 (2010): 8290.

[12] Sikkema, Richard, et al. "The European wood pellet markets: current status and prospects for 2020." Biofuels, Bioproducts and Biorefining 5.3 (2011): 250-278.

[13] Nunes, L. J. R., J. C. O. Matias, and J. P. S. Catalão. "Energy recovery from cork industrial waste: Production and characterisation of cork pellets." Fuel 113 (2013): 24-30.

[14] Carneiro, Patrícia, and Paula Ferreira. "The economic, environmental and strategic value of biomass." Renewable Energy 44 (2012): 17-22. 
[15] Smith, T. Pieter, and H. Martin Junginger. "Analysis of the global production location dynamics in the industrial wood pellet market: an MCDA approach."Biofuels, Bioproducts and Biorefining 5.5 (2011): 533-547.

[16] Goh, Chun Sheng, et al. "Wood pellet market and trade: a global perspective."Biofuels, Bioproducts and Biorefining 7.1 (2013): 24-42.

[17] Sikkema, Richard, et al. "The international logistics of wood pellets for heating and power production in Europe: Costs, energy-input and greenhouse gas balances of pellet consumption in Italy, Sweden and the Netherlands." Biofuels, Bioproducts and Biorefining 4.2 (2010): 132-153.
[18] Selkimäki, Mari, et al. "Present and future trends in pellet markets, raw materials, and supply logistics in Sweden and Finland." Renewable and Sustainable Energy Reviews 14.9 (2010): 3068-3075.

[19] Fernandes, U., and M. Costa. "Potential of biomass residues for energy production and utilization in a region of Portugal." Biomass and Bioenergy 34.5 (2010): 661-666.

[20] Kopetz, Heinz. "Build a biomass energy market." Nature494.7435 (2013): 29-31.

[21] Mola-Yudego, Blas, Mari Selkimäki, and José Ramón González-Olabarria. "Spatial analysis of the wood pellet production for energy in Europe." Renewable Energy 63 (2014): 76-83. 